Comparison of the Properties of Shape Memory Actuators and Thermobimetals

P. Tautzenberger, G. RAU GrabH \& Co., Pforzheim, FRG

\title{
Introduction
}

To find out the optimum type of actuator for a given application, one has to pay attention to numerous criteria like simplicity of the construction, required volume, type of activating energy, velocity of actuation process, reliability and precision, working life, economical aspects, and so on.

On the field of thermal actuators besldes shape memory actuators there are some classical actuators like thermobimetals and wax actuators. The present paper deals with the comparison of the properties of shape memory actuators and thermobimetals.

\section{Shape Memory Actuators}

Shape memory actuators are made out of shape memory alloys and due to a thermoelast ic martensitic transformation after a certain treatment they show a temperature-depending shape change $(1-6)$. The characteristic properties of shape memory actuators can be sumnarized as follows:

- Performance of the complete mechanical work in a selected and relatively narrow temperature range (hysteresis)

- High mechanical work per unit volume

- Possibility to exhibit different types of shape change (elongation, contraction, bending, torsion)

- The shape memory effect can be restricted to certain parts of the element.

The properties and applications of shape memory actuators have already been described in detail in a previous paper in these proceedings.

\section{Thermobimetals}

\subsection{Fundamental Aspects of Thermobimetals}

Thermobimetals are sheet composite materials which consist of at least two components with differing coefficients of thermal expansion. Therefore a thermobimetal bends on heating or cooling. Thermoblmetals are known since more than 200 years. They are used as simple and cheap elements for temperature-depending actuation in the fleld of measuring, controlling and regulating technics (7-9).

The most important criterium for the selection of the components of thermobimetals is the thermal expansion. The component with the smaller thermal expansion is called passive component and the component with the larger thermal expansion is called active component. 
Very high thermal expansion show the alloys of manganese with additions of copper and nickel, iron-nickel alloys with additions of manganese, chromium and molybdenum as well as austenitic stainless chromium-nickel steels.

A well-known alloy with a low thermal expansion is the iron-nickel alloy with 368 nickel, which is called Invar. In addition ironnickel alloys with 428 and 468 nickel as well as ferritic stainless steels are passive components of great importance.

To produce a thermobimetal one has to clad suited components by cold or hot rolling. In general thermobimetals are used with a final cold working rate of 20-308.

The thermal sensitivity of a thermobimetal is characterized by the so-called specific thermal curvature ("flexivity") which can be calculated according to the formulae in the german standard DIN 1715. The specific thermal curvature is not a constant. Therefore the temperature-deflection curve of a thermobimetal is not fully linear, but it looks like the schematical curve shown in Fig. 1 . The nominal specific thermal curvature of a thermobimetal according to the german standard DIN 1715 is valid for the temperature range from +20 to $+130^{\circ} \mathrm{C}$.

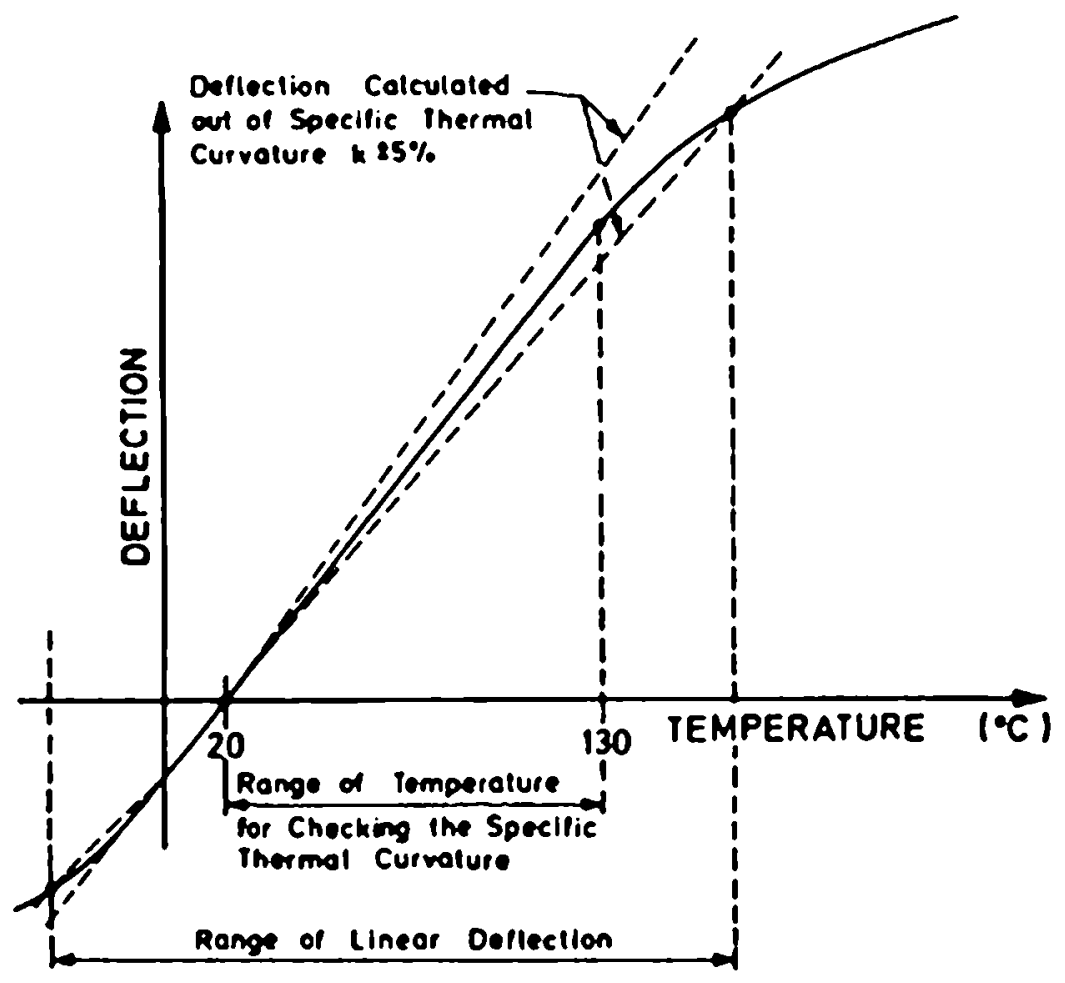

Pig. 1: Schematic temperature-deflection curve of a thermobimetal.

According to Fig. 1 the range of linear deflection is the temperature range in which the measured thermal deflection does not deviate more than \pm 5 from the calculated value using the nominal specific thermal curvature. Beyond the range of linear deflection, there is a decreasing, but for many applications sufficient deflection. Hence the range of application often exceeds the range nf linear defiection. 
The upper 1 imit of application 18 the highest temperature at which no permanont change of the properties of the thermoblmetal occurs. Thls temperature corresponds to the recrystallization temperature of the thermoblmetal for long time application and the usual cold working degree of 20-30s.

The groat number of possible component combinatlons has load worldwlde to more than 100 sorts of thermoblmetals. In Table 1 there are 118 ted the components and somo additional data for

\begin{tabular}{|c|c|c|c|c|c|}
\hline Dimated & pomponimt & $\begin{array}{l}\text { Parime } \\
\text { componomt }\end{array}$ & 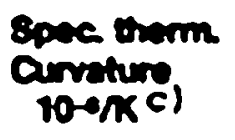 & $\begin{array}{l}\text { Pange of } \\
\text { Uneer Doninction } \\
\text { - C }\end{array}$ & $\begin{array}{l}\text { Upoper linim } \\
\text { of Apolication } \\
\text { "C }\end{array}$ \\
\hline $\operatorname{To} 677 A^{a}$ & henecouns & Fensos & 285 & $-20 w+200$ & 450 \\
\hline $182010^{a)}$ & MTOUTEND & fencas & 39.0 & $-2010+200$ & 350 \\
\hline NS b) & MnNisOuno & Fontzec06 & 43.8 & +20 to +230 & 350 \\
\hline$R S$ b) & XRCANis 8 & FeNi32001471,5 & 18,0 & -20 to +400 & 650 \\
\hline$F A^{b)}$ & Xeanis 8 & xecon & 9.5 & $-2010+\infty 00$ & 550 \\
\hline
\end{tabular}

a) Denotation according to DIN 1715 .

b) MS, RS, RR are trade names of G. RAU Gmbll * Co.. Pforzheim.

c) Nomlnal value for tho temperature range from $+20^{\circ} \mathrm{C}$ to $+130^{\circ} \mathrm{C}$.

Table 1: Components and propertles of thermoblmetals.

different sorts of thermoblmetal. In Flg. 2 there are shown examples for different types of thermoblmetal-elements like strlps, dlscs, splral and hollcal colls, In which the respective shape change 18 based on the temperature-depending bending of the shect composito materlal.

Thermoblmotals especlally are used as simple and cheap actuators in a large number of: technical flelds like automotive industry, electrotechnical flefds and hoating systems $(8,9)$.

\subsection{Comparison of the Propertles of Shape Memory Actuators and} Thermobimetals

The different basls for the shape change of shape memory actuators and thermoblmetals naturally $1 \mathrm{mpl}$ les drastic differences concerning the properties of these two groups of elements.

The propertles of shape memory actuators have already been expla1ned in detall in a previous paper in these proceedings. 


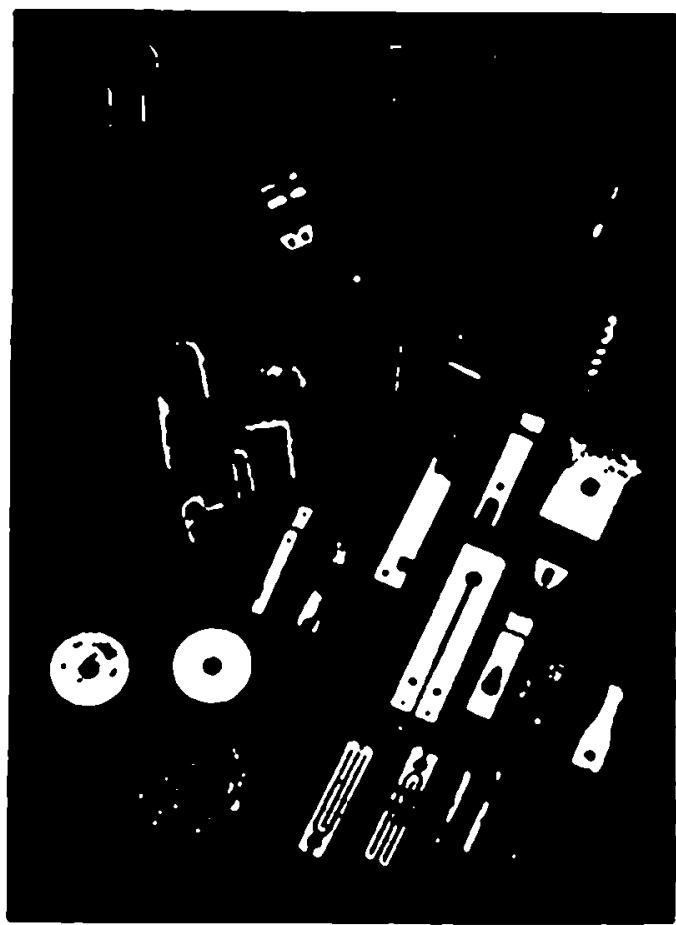

F1g. 2: Examples of possible types of thermobimetal-elements.

The characteristic properties of thermobimetals can be summarized as follows:

- Linear deflection versus temperature change

(no hysteresis)

- Linear deflection up to about $600^{\circ} \mathrm{C}$

- Iimit of application about $650^{\circ} \mathrm{C}$

- Extremely high stability of the effect of shape change (up to about 20 millions of thermal cycles).

The greatest difference between thermobimetals and shape memory actuators is noticed at the temperature-deflection curve. Fig. 3 shows the temperature-deflection curve for a cantilever strip of Cu-2n-Al with a two-way bending effect of 18 and for the standard thermobimetal TB 1577A with the same dimensions. The shape memory element shows at the free end a reversible deflection of about $25 \mathrm{~mm}$ in a temperature range of about $40 \mathrm{~K}$. By a two-way effect of more than 18 naturally one would get an even greater deflection. The standard thermoblmetal TB 1577A with the same geometry shows a deflection of about $1,5 \mathrm{~mm}$ for the mentioned temperature range of $40 \mathrm{~K}$. If one looks for a temperature range of $200 \mathrm{~K}$ then the thermobimetal makes a deflection of about $7,5 \mathrm{~mm}$ (7).

As one can see in Fig. 3 the temperature-deflection curve of shape memory elements with a two-way effect exhibits a hysteresis which amounts to 10-30 $\mathrm{K}$ depending on the type of alloy and the material treatment. In contrast to the shape memory actuators thermobimetals show practically no hysteresis in the temperature-deflection curve. But with thermobimetals one can fabricate mechanically dished discs. so-called snap action discs, which show a sudden displacement and a hysteresis in their temperature-displacement curve. In general thermobimetal snap action discs are used in applications with a relatively small displacement and force (9). 


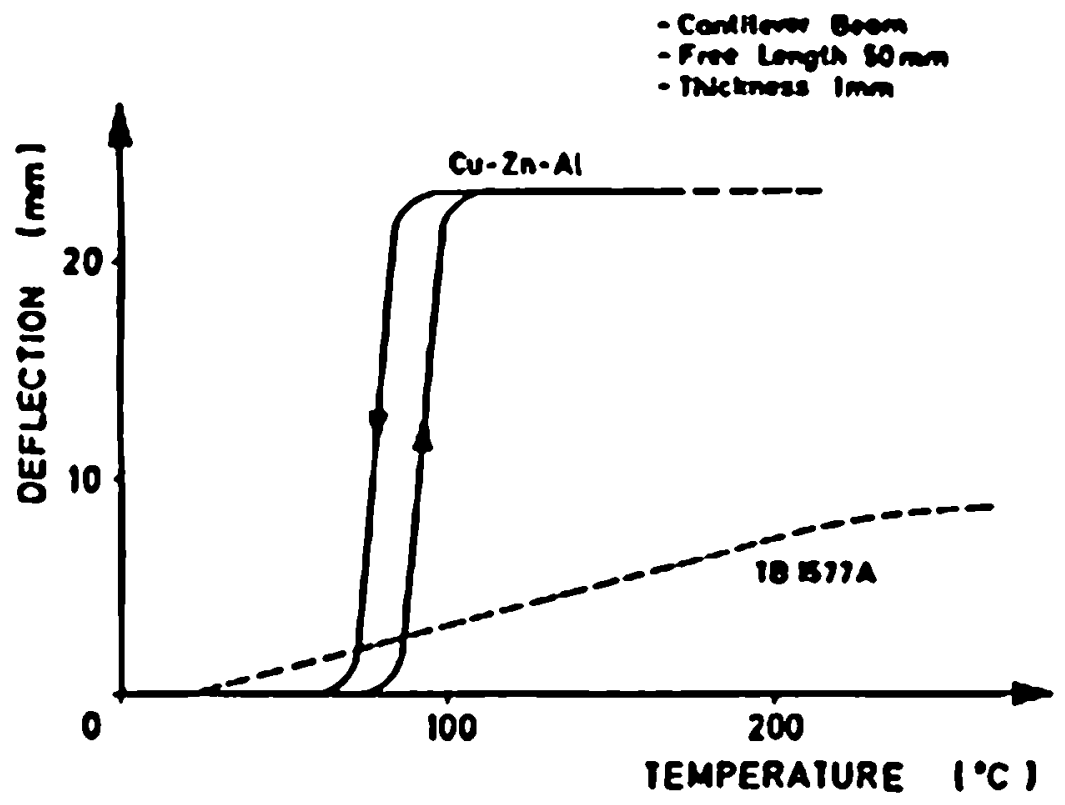

F1g. 3: Temperature-deflection curves of a cantilever strip of Cu-zn-Al with a two-way bending effect of 18 and of a standard thermobimetal TB 1577A with the same dimensions lat room temperature flat strip, thlckness $1 \mathrm{~mm}$. Free length $50 \mathrm{~mm}$ ).

If one uses the corresponding formulae from tho technical literature for the standard thermobimetal TB 1577A with a tomporature change of $100 \mathrm{~K}$, one gets a working capaclty por unit volume of about $0,02 \mathrm{w} / \mathrm{m}^{\prime}$. With a greater temperature differenco naturally one gets a groater working capacity (8).

Shapo memory actuators with a two-way effect exhibit a working capacity per unlt volume of about $1-5 \mathrm{~kJ} / \mathrm{m}^{3}$ depending on the group of alloy, the magnitude of effect and stress. Th1s work1ng capacity 18 achioved with a temperature change of only about $30-40 \mathrm{~K}$ and 18 much groater than with thermoblmetals. In Table 2 there are shown some mechanical properties of shape merory alloys and thermoblmetals. Since the admissible stresses for thermoblmotals and shape memory actuators aro nearly of the same magnitudo, the great working capaclty of shape memory actuators 18 primarlly due to the great displacement (magnitude of effect).

Thermoblmetals can show only bending as a type of shape change, 80 that in general the materlal volume does'nt work completely. In contrast to this, certain types of shape memory actuators ilke stralght tensile wires with homogeneous stress distribution use 1008 of the working capaclty of the volume.

Shape memory olements exhlbit a higher strength in the austenitic state than in the martensitic one. Therefore thase elements only on heating can generate work agalnst a bias force. On the contrary on cooling the low-temperature structure with a small strength 18 formed. so that external forces whlch are opposite to the element reversion would cause a degradation of the shape memory effect. On the other hand thermoblmetals can generate work both on heating and on cooling. 


\begin{tabular}{|c|c|c|c|c|}
\hline Proponts & min & anding & $\begin{array}{l}\text { a) } \\
\text { anthy }\end{array}$ & $\begin{array}{c}\text { Thannobimetals } \\
\qquad 20^{\circ} \mathrm{Cb}\end{array}$ \\
\hline $\begin{array}{l}\text { Admlacible Strases } \\
\text { Oedm (N/mmm) }\end{array}$ & 250 & 76 & 100 & $200-250 \mathrm{cl}$ \\
\hline $\begin{array}{l}\text { Tensis Slronoth } \\
\text { (N/mml }\end{array}$ & $800-1000$ & $400-700$ & $700-800$ & $600-900$ \\
\hline Elang ton (x) & $40-50$ & $10-15$ & $5-6$ & $2-10$ \\
\hline
\end{tabular}

a) The propertles depend on different parameters (e.g. alloy composition and temperature).

b) Final cold working rato of 20-30

c) The thermobimetal type RS (Table 1$)$ is an exception and can be loaded up to $500 \mathrm{~N} / \mathrm{mm}^{2}$.

Table 2: Some mechanical properties of shape memory alloys and thermobimetals.

As one can 800 in Table 1 for thermoblmetals tho range of linear deflection covers values from -20 up to about $600^{\circ} \mathrm{C}$ and the maximum limit of application for long tire is $650^{\circ} \mathrm{C}$. In addition thermobimetals exhlbit a high stabllity of the shape change effect.

Shape memory alloys can exhiblt $A_{g}$-temperatures between about $-150^{\circ} \mathrm{C}$ and $+150^{\circ} \mathrm{C}$ depending on the group of alloy. In contrast to the thermoblmetals shape memory actuators show a restricted stabllity of the shape change effect (7).

\section{Closure Remark}

Both shape memory actuators and thermoblmetals have specific properties which, depending on the requirements, can lead to advantageous solutions. For technical and economlcal reasons a mutual interchangeability of these actuators is possible only for a very ilmited number of applications.

\section{References}

(1) J. Perkins: Mat. Sc1. Eng. 51 (1981) 181-192.

(2) P. Tautzonberger, D. Stockel: zeltschrift fur wirtschaft1iche Fertlgung 78 (1983) 10, 486-488.

(3) P. Tautzenberger, D. Stockel: zeitschrift fur wirtschaftliche Fertlgung 81 (12) (1986) 703-708.

(4) T.W. Duerig, J. Albrecht, G.H. Gessinger: Journal of Metals 34 (12) (1982) 14-20.

(5) L. Delaey, A. Deruyttere, E. Aernoudt, J.R. Roos: INCRA REPORT 1978.

(6) P. Tautzenberger: Magazin Neue Werkstoffe 1 (1987) 20-23.

(7) P. Tautzenberger, D. Stockel: METALL 41 (1987) 26-32.

(8) G. RAU GmbH \& Co.. Pforzhelm: Thermobimetalle, Plrmenschrlft 1979.

(9) F.E. Schnelder U.a.s Thermoblmetalle, Expert-Verlag (1982) 93-104. 